\title{
Die Klage annehmen
}

\section{Jean Martin}

Dr. med., Mitglied der Redaktion

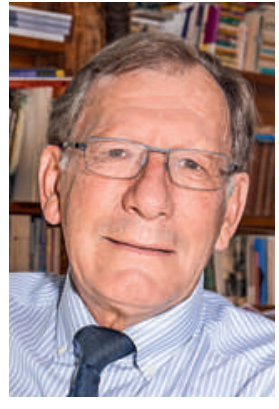

Marion Muller-Colard promovierte in Strassburg in Theologie und war Krankenhausseelsorgerin in Mülhausen. Sie befasste sich mit der biblischen Geschichte von Hiob, dies vor allem vor dem Hintergrund beruflicher Begegnungen mit Personen, die durch ihre Erkrankung bitter und rebellisch wurden. Ihr neuestes Buch [1] sorgt für viel Interesse, nicht nur in christlichen Kreisen. Alter und Leiden. «Hohes Alter ist oft ein Missstand, der sich langsam und stetig bis zum Tod hinzieht. Und oft werden Menschen, die eigentlich ihre Sättigungsschwelle erreicht haben, mit allen Mitteln am Leben erhalten. Dabei besteht keine Vorstellung darüber, was es heisst, ohne Appetit (auf Leben) zu leben. Man müsste vom Tisch aufstehen können. Stattdessen werden wir an unserem Stuhl festgebunden und sind dazu verdammt, einer nicht enden wollenden Mahlzeit beizuwohnen". "Physisches Leid birgt die diabolische Macht, sich an einen für andere unzugänglichen Ort zurückziehen zu können. Diabolisch, weil es Diabolus ist, der trennt, und der Schmerz trennt uns von anderen und von uns selbst». Man könnte meinen, dass ein Autor, der diese Worte schreibt, das Thema Sterbehilfe ansprechen will, aber das ist nicht der Fall. Die Krankheit eines Kindes als initiale Erfahrung. Marion Muller ist geprägt durch die Erfahrung, dass eines ihrer Kinder im Alter von wenigen Monaten nur knapp eine Pneumonitis überlebt hat. «Lange Monate mit künstlicher Beatmung, eine akut lebensbedrohliche Situation, Unsicherheit, Benommenheit. Das musste durchlebt werden, ich verharrte ohnmächtig im Dunkel.» «Ich habe damals fremden Kindern literweise meine Milch abgegeben. Die Schläuche, die meinen kranken Sohn ernährten, beraubten mich meiner Funktion als Milchspenderin. Um also etwas zu produzieren, saugte ich meine Milch für andere ab.» Verlust der Sinnhaftigkeit: «Wozu dient ein funktionierendes Herz, wenn wir vom Ideen- und Wertesystem, aus dem die Sinnhaftigkeit unseres Seins erwächst, abgetrennt sind?» Später: «Mein Sohn war wieder gesund, ich nicht. Bedrohung hatte mich voll im Griff und nahm mir meinen Appetit auf Leben.»

Wir hätten gerne vertragliche Sicherheit. Als Pastorin spricht sie von der Beziehung des Patienten zur Vorsehung und betont dabei, dass "wir oft eine Art Vertragsverhältnis mit Gott haben. Und wenn uns der Begriff Gott hier nicht sinnhaft erscheint, so haben wir doch ganz sicherlich ein Vertragsverhältnis mit der Gerech- tigkeit.» Wir glauben an eine vergeltende Gerechtigkeit. Wenn aber das, was uns geschieht, nicht mit dem übereinstimmt, was wir als gute Menschen erwarten, sagen wir in unserer Wut oder Frustration: «So war das nicht vorgesehen, das stand nicht im Vertrag». Fakt ist jedoch, dass «Glück und Unglück gleichermassen ungerecht sind».

Diese Verträge sollen uns absichern und wir produzieren sie, «seit der Mensch Mensch ist und die Götter mit Gebeten zu beruhigen oder zu verführen sucht, seit er die Grabstätten mit Werkzeugen oder Schmuckgegenständen ausstattet und so mit jemandem die Sicherheit der Stätte aushandelt». Wir sprechen in diesem $\mathrm{Zu}$ sammenhang auch vom «Schlaf der Gerechten». Aber, so Marion Muller-Colard, wir schlafen den Schlaf jener, die die Wachsamkeit und die Verantwortung an Gott (oder andere) abgeben, «den Schlaf jener, die glauben, durch einen Zaun geschützt zu sein».

Krankenhausseelsorgerin. «Ich habe erlebt, wie durch Krankheit viele Verträge gebrochen wurden. So ging es auch diesem portugiesischen Einwanderer, der hart in Frankreich arbeiten wollte, bis er sich in seinem Land ein Haus kaufen konnte. Es gelang ihm, seine Pläne zu verwirklichen, aber sechs Monate nach seiner Pensionierung machte der Krebs seinen Lebensvertrag zunichte. Seine Augen suchten in den meinen nach einer Erklärung. In diesem Zimmer entdeckten wir die unergründliche Abwesenheit von Sinnhaftigkeit.» Wie sollen wir Worte finden, um den vom Leben Gezeichneten wieder Mut zum Sein zu vermitteln? «Ich suche Mittel und Wege, die es mir erlauben, den Glauben als Elan, als dynamische Kraft zu pflegen. Ich nehme jede Hilfe, die sich im Kampf gegen das Chaos einsetzen lässt. Dabei behaupte ich nicht, Gott wirklich zu 'kennen'. Mein Ansatz ist viel pragmatischer. Ich nehme alles an, was dem Menschen hilft, auf der Welt zu sein.» «Die Arbeit als Seelsorgerin besteht in der täglichen Begegnung mit der Klage. Als ich mich auf das un sichere Terrain des Krankenhausmilieus vorwagte, wusste ich, dass meine Arbeit eher eine annehmende als eine abwehrende Haltung voraussetzt.» «Es gibt kein Universitätsstudium, das auf die Ohnmacht vorbereitet». «Echte Freunde erkennt man daran, wie sie mit der Präsenz von greifbarem Unheil umzugehen wissen, ohne zu flüchten oder sich in leeren Tröstungen zu ergehen.» Dies gilt für den Seelsorger wie für alle anderen Menschen. 